\title{
A dialética Senhor-Escravo como chave hermenêutica em Bin Kimura
}

\section{The Master-Slave dialectic as a hermeneutic key in Bin Kimura}

Guilherme Ludovice Funaro ${ }^{1}$

\footnotetext{
${ }^{1}$ Psiquiatra pelo Instituto de Psiquiatria do HCFMUSP, Membro da Sociedade Brasileira de Psicopatologia Fenômeno-Estrutural

E-mail: guilhermeluodvice@yahoo.com
} 


\title{
Resumo
}

O presente estudo visa buscar uma base filosófica hegeliana, explorada na obra Fenomenologia do Espírito, quanto à consciência-de-si e sua gênese, a fim de contextualizar uma estruturação que conceba a consciência não erigida em bases solipsistas, mas sim como um construto social, apreendendo a estrutura da alteridade em seu núcleo mais íntimo, num embate entre forças antagônicas que clamam para si reconhecimento, na forma da alegoria Senhor-Escravo. A partir dessa base, procuro exemplificar empiricamente como se instaura tal dinâmica, para em seguida abordar a esquizofrenia, em especial sob a perspectiva do autor Bin Kimura, que compreende a clínica esquizofrênica de forma muito semelhante, com base em tal embate de forças, que se processaria de forma não integrativa. Tento, então, iluminar a clínica esquizofrênica deste autor à luz de uma chave de leitura próxima ao pensamento hegeliano, traçando possíveis pontos de convergência e divergência quanto as suas perspectivas.

Palavras-chave: Hegel; Esquizofrenia; Bin Kimura; Consciência-de-si.

\begin{abstract}
The following study aims at seeking a Hegelian philosophical basis, explored in Phenomenology of the Spirit, towards self-consciousness and its genesis, in order to contextualize a structure that conceives consciousness not in a solipsistic base, but rather as a social construct, that apprehends the structure of otherness in its intimate nucleus, as in a struggle between antagonistic forces, each claiming recognition for itself, in the form of the allegory Master-Slave. From this basis, I exemplify empirically how this dynamic establishes itself, aiming at discussing schizophrenia, thru the perspective of Bin Kimura, whose schizophrenic clinical descriptions are, in many ways, close to this idea of a non-integrative clash of antagonistic forces. Finally, I try to conceive a parallel between Kimura's considerations on schizophrenia seen through a Hegelian perspective, gathering convergence and divergence between both authors.
\end{abstract}

Keywords: Hegel, Schizophrenia, Bin Kimura, Self-Consciousness. 


\section{Introdução}

Todo processo reflexivo impõe a interposição de uma distância entre si e si mesmo. Há sempre dois polos: aquele que reflete e o que é refletido.

Mesmo na reflexão mais prosaica, acerca de uma hipotética viagem, por exemplo, o que se processa, e ficará mais claro no transcorrer deste trabalho, é que a consciência se duplica. Não conjecturo a respeito da viagem, mas $e u$ reflito se $e u$ viajarei e nesse sentido é que se dá a distância entre dois eus.

Um dos polos guarda o fundamento ontológico desse ser propriamente, que é aquele eu que reflete, como um ponto zero de referência no mundo. No entanto, quando esse processo reflexivo, que emana desse polo, volta-se sobre si mesmo, tem-se uma perscrutação da própria perscrutação, uma reflexão acerca da própria capacidade reflexiva. Fala-se aqui em ipseidade como um modo da consciência, particularmente da consciência de si, compreendida não como a consciência de um ego, mas como a consciência da própria consciência. Modalidade essa na qual aquele que reflete e o refletido são uma coisa só. Ipseidade refere-se também ao sentimento de ser o centro das próprias experiências, é o fenômeno tácito fundante das experiências, que garante uma distinção entre mim e aquilo que percebo como objeto (Stanghellini, 2003).

É justamente esse modo, que encerra tal processo autorreflexivo, que precisa ser explorado, a fim de que se compreenda como se estrutura, fundamentalmente, a esquizofrenia.

\section{"A verdade da certeza de si mesmo"}

No capítulo IV da obra Fenomenologia do espírito, "A verdade da certeza de si mesmo", perscruta-se o processo de constituição de uma ciência da experiência da consciência, no que tange à adequação entre saber e um dado objeto. Traça-se, propriamente, uma genealogia da consciência.

Havia uma tradição quanto a conceber a ideia de conhecer como adequação: conhecer um cavalo era permitir que o intelecto se adequasse à forma deste cavalo. A verdade, a medida deste saber, estava para além desta consciência, residindo nos objetos. Do título do capítulo já é possível depreender que se trata de outro tipo de verdade - aquela como certeza subjetiva de si.

Até então, tinha-se que a verdade se doava para a consciência, como algo distinto dela: a verdade deste copo, desta mesa, reside como algo "Em-si". No entanto, quando a consciência 
tenta apreender esta verdade, cai em dificuldades, pois não consegue adequar sua certeza à verdade do que está para além dela.

Exemplo do que foi explicitado acima é a dificuldade em tentar apreender, por uma via nominalista, um dado objeto qualquer: posso recorrer a um sistema de coordenadas e propriedades, a fim de dissecá-lo em sua integralidade, em toda sua "verdade". No entanto "a certeza vem a perder-se na verdade" (Hegel, 2014, p. 135).

A consciência depara-se com um obstáculo que é a apreensão de algo que está para além dela, não plenamente apreensível pela via da linguagem, via conceitual, por exemplo. A própria linguagem, que comunica intersubjetivamente essa apreensão, é uma construção social. Daí que a consciência percebe que esse "Em-si" é apenas "uma maneira como o objeto é somente para um Outro" (Hegel, 2014, p. 135).

A fenomenologia hegeliana compreenderia a maneira como a consciência erraria, alienando-se frente ao que lhe aparece. No entanto, tais erros conduzem dialeticamente a um tipo de saber, que não é propriamente o desfecho de um processo, mas sim o próprio percurso, com seus limites, um aprendizado internalizado reflexivamente. É o que se dá, quando na sequência diz surgir "uma certeza igual à sua verdade" (Hegel, 2014, p. 135). Tal peculiaridade se daria como numa espécie de paralelismo ou pensamento reflexivo no qual se desvela que a estrutura do objeto é a mesma do Eu: essa certeza, da consciência, que tenta apreender a verdade do objeto, do que está para além dela, também é verdade, tomando-se a certeza como seu objeto (sob a perspectiva de um Eu) e a consciência seria para si mesma verdadeira. Daí que a consciência seria também um "ser outro", pois ela guardaria a mesma estrutura da alteridade.

Essa estrutura da consciência dos objetos é a mesma estrutura da consciência de si, ou consciência da própria consciência.

Ora, se houvesse uma plena subsunção do objeto à consciência, na verdade não haveria distinção, propriamente, entre consciência e alteridade. Refletir sobre a consciência do objeto é refletir sobre os meandros desta própria consciência e constatar que tal experiência de alteridade dá-se na própria experiência da consciência para consigo própria. Nesse sentido, o conceito de Eu é sedimentado relacionalmente, emerge de intersubjetividades (o Eu sempre traz consigo um Outro) e não de maneira solipsista.

A consciência conhece não propriamente porque promove uma subsunção plena do objeto, mas conhece sim porque há algo de semelhante entre a estrutura dos objetos e a estrutura da própria consciência. Nesse sentido, o que se passa é uma experiência de duplicação, na qual a consciência tem a experiência de que a estrutura da consciência de si tem a mesma estrutura da consciência do objeto. 


\section{O desejo}

Hegel afirmará que "a consciência-de-si é desejo" (Hegel, 2014, p. 140). Em que medida isso pode ser compreendido?

Kojève (1947) nos diz que quaisquer comportamentos cognitivos contemplativos (como a razão, o pensar, o entendimento) de um ser não conduzem à consciência de si, pois nessa atitude o homem fica tomado pelo que contempla. Tal movimento de retorno a si somente pode ser feito pelo Desejo.

Isso ocorre pois, se a individualidade afirma-se inicialmente como certeza de si mesma, é o Desejo quem lhe apresenta essa oposição ao não Eu. O Desejo é a própria expressão da falta, que aparece instanciada no objeto, é aquilo que lhe impulsionará à ação.

Tal ação, para sua satisfação, implicará na negação do objeto (a fome, para sua satisfação, implica na destruição, como transformação do alimento). No entanto, se há uma destruição de uma realidade objetiva, cria-se, por assimilação de uma realidade estranha, uma realidade subjetiva. Ele incorpora a mesma qualidade daquilo que deseja.

O Desejo humano, no entanto, é diferente do desejo animal na medida em que ele deseja um outro Desejo: “A satisfação do desejo é a reflexão da consciência-de-si sobre si mesma, ou a certeza que veio-a-ser verdade" (Hegel, 2014, p. 141). Sua plena satisfação somente se dá quando se duplica.

A consciência procura-se a si por meio do objeto. Seria como dizer que na satisfação da fome, não é simplesmente o objeto, o alimento, que está em questão, mas sim a consciência sem o alimento, contempla-se negativamente como consciência alimentada e essa negação é o verdadeiro motor da consciência. Kojève denominará este Eu de uma "negatividade negadora", cuja característica é não ser estático, mas um tornar-se.

Tome-se o exemplo da satisfação sexual entre duas pessoas. O Desejo não repousa na satisfação corpórea, como mero objeto, mas sim no desejar o desejo do outro; desejo ser desejado pelo outro. Numa relação assimétrica entre um sujeito e um objeto, a satisfação deste Desejo como consciência-de-si não opera, mas somente o faz numa relação em que ambas as partes se reconhecem como sujeitos e nesse sentido duplicam-se: encontro-me no outro. O que está em jogo é uma filosofia do reconhecimento, não como mera constatação, mas sim propiciando mútua existência - existência como atributo de valor, não como atestado de um fato, e nesse sentido, mais do que se depositar sobre algo, o Desejo é desejo de um valor. 
Mesmo quando desejo um objeto inútil para minha vida biológica, como ouro, o que está implícito aqui é que desejo o objeto de desejo de meus semelhantes e nesse sentido "a história humana é a história dos Desejos desejados" (Kojève, 1947).

Para que o ser seja verdadeiramente um humano, distinto dos demais animais, é preciso que o seu Desejo prevaleça sobre o desejo animal. Se todo desejo é a expressão de um valor e o valor supremo para um animal é a conservação de sua vida, logo o Desejo humano deve se sobrepor a tal desejo de conservação e o ser, para tornar-se humano, deve arriscar sua vida. Falar da Consciência-de-si é falar em arriscar a vida.

Do que se trata esse arriscar a vida? Não se trata de um fim vital, o que se deve depreender de tal colocação. Desejar o Desejo não se trata de tornar-se o objeto desejado, mas sim que o valor, por mim representado, seja o valor desejado por um outro, ou de que a alteridade reconheça o meu valor como seu valor. Arriscar a vida é, em última instância, uma luta pela demanda de reconhecimento, pois um ego somente existe para si se existe para outro.

A origem da Consciência-de-si, como um atributo distintivo do ser humano diante dos demais animais, envolve um embate de forças antagônicas que clamam por reconhecimento, que se lançam num embate arriscando-se a uma desintegração, a fim de impor-se ao outro como valor superior.

O ponto curioso dessa alegoria é que se levada a cabo tal luta, uma das partes, se não ambas, morreriam. No entanto, se tal processo ocorresse dessa forma, não haveria reconhecimento possível, nem realização da humanidade, pois perde-se aquele que poderia me reconhecer.

Não se deve esquecer que se trata de uma genealogia da consciência, como anunciado mais acima. Logo, isso implica que para o ser-humano se processar como Consciência-de-si, essa realidade precisa ser múltipla e figurar "comportamentos humanos ou antropogênicos essencialmente diferentes" (Kojève, 1947). Em outras palavras, a Consciência-de-si nascente incorpora a presença da alteridade em sua gênese. A todo momento parece ambíguo na obra de Hegel se ele discorre sobre uma dinâmica intersubjetiva ou se a referência é metafórica, para figurar uma dinâmica interna da própria consciência em uma dupla figuração como sujeito e objeto. Valho-me desta última alternativa para defender minha tese.

Num primeiro momento da gênese desta Consciência-de-si, ela é Ser-para-si, quer dizer, afirma-se de maneira senhorial pela exclusão de tudo que não é ela, como um Eu isolado e este Outro, não integrado, é visto pelo prisma da negatividade (do não-Eu), sob o signo da ameaça a ser neutralizada e destruída. Nesse embate de forças, no entanto, ambos os lados precisam "sobreviver" ao final da luta. Lutam, pois representam disposições antagônicas e almejam o 
reconhecimento da outra parte, no entanto uma das partes cederá nesse reconhecimento, terá medo da outra parte, enquanto a outra será reconhecida. Em outras palavras, uma será Senhor, a outra, Escravo.

Senhor é a representação de uma existência autônoma e Escravo a de uma dependente. Fala-se de uma relação dialética, pois Senhor, a despeito de ser Senhor, é também escravo do Escravo, quando percebe que necessita dele para seu reconhecimento e que, em última instância, seu aniquilamento representaria sua própria destruição. $\mathrm{O}$ mesmo vale para o Escravo, que se reconhece como senhor do Senhor, quando da constatação de que este último depende dele para seu reconhecimento. Instaura-se um embate, cujo resultado não é almejar a morte do seu adversário, mas suprimi-lo dialeticamente, que consiste em suprimir, mas conservando o suprimido.

Em suma, Consciência-de-si deve ser compreendida não propriamente como consciência de um Eu, mas sim como estrutura reflexiva da própria consciência. A Consciênciade-si tem a mesma estrutura da consciência dos objetos e encerra a presença da alteridade em sua estrutura, num embate de forças, no qual geneticamente este outro não integrado é visto como ameaça e por isso passível de ser eliminado. No entanto, a Consciência-de-si é Desejo, instaurando uma dinâmica distintiva aos seres-humanos, uma dinâmica por reconhecimento, na qual a eliminação do outro seria sua própria eliminação.

Instaura-se então um embate de forças entre dois polos antagônicos, Senhor e Escravo, cuja tensão desembocará numa "supressão dialética" (Kojève, 1947). Uma síntese de como tal embate de forças antagônicas desembocará numa transmutação de ambos os polos é dada por Bin Kimura: "Descobrir num outro um eu que me escapa, desvela uma alteridade, cuja contrapartida pode me fazer descobrir em mim mesmo um outro que me é desconhecido" ( 'Découvrir en l' autre un moi qui m'échappe, dévoile une alterité que en retour peut me faire découvrir en moi-même un autre qui m'est inconnu”). Nesse sentido é que a consciência se fundamenta num constructo social e não solipsista.

\section{Considerações acerca da esquizofrenia}

A exposição acima tem por finalidade uma construção genética da consciência, que poderia dar-nos subsídios para pensar como compreender a desestruturação esquizofrênica, com base na estruturação da consciência de si.

Tome-se então uma forma de intencionar particular da consciência, como meramente ilustrativa: Eu observo o pássaro. Na impossibilidade de subsumir tal objeto - o pássaro, no 
caso - como um objeto de consciência em sua totalidade é que a consciência se abre de forma reflexiva sobre si própria, para constatar que tem a mesma estrutura dos objetos.

O embate de forças está dado mediante esses dois polos, o "Em-si" do objeto e "Serpara-si” do sujeito. À consciência é facultado conhecer tal objeto, pois examinando-se como se estrutura a própria consciência (como consciência-de-si), esta configura-se à semelhança da estrutura dos objetos, guardando em si a presença da alteridade também na forma de um "Emsi" e um "Ser-para-si".

A figura da especularidade, como num jogo de espelhos, é pertinente, pois supondo-se a consciência como um espelho, que figura o objeto - no caso da frase em questão, o pássaro o que se tem agora é um espelho refletindo o outro, reproduzindo-se ad infinitum (esta é a imagem da consciência-de-si).

Gramaticalmente podemos figurar esse desdobramento da seguinte maneira: "Eu observo o pássaro", cujo sujeito da frase é o "Eu" e o predicado "o pássaro". Teríamos então um desdobrar desse polo do sujeito: Eu reparo que eu observo o pássaro.

Nesta segunda frase temos então um "Eu" sujeito e um "eu" diluído no predicado. Apesar de gramaticalmente distintos, ambos são psicologicamente experimentados, numa experiência normal, como coincidentes, ou seja, o mesmo eu que observa o pássaro é o mesmo eu que repara que observa o pássaro. Tem-se um eu que reflete acerca de um eu refletido, embora sejam psicologicamente e empiricamente o mesmo.

Empiricamente a perspectiva de um $\mathrm{Eu}$, ocupando um ponto zero de orientação, de onde professo um aqui e um ali, é múltipla: posso ocupar a posição do "Eu observo o pássaro" ou "Eu reparo que eu observo o pássaro". Além de múltipla, é dialética, pois esse Eu é também um não-Eu (como Tu).

Nesse sentido é que a estrutura da consciência-de-si encerra um embate de forças antagônicas, que clamam, cada uma para si, a afirmação de um Eu independente, como se cada um desses múltiplos Eus fosse o Senhor, como ponto zero de referência dessa autoafirmação.

No entanto, como vimos na explanação acima, a Consciência-de-si é Desejo. Desejo este por reconhecimento, de tal forma que o jogo de forças deve permanecer em constante tensão, pois para que haja um reconhecido é preciso que alguém o reconheça. Logo, a Consciência-de-si precisa encerrar um embate na forma de um "Em-si" e um "Ser-para-si", o que chamei acima de um Eu e um não-Eu (ou Tu).

Empiricamente, vive-se tal embate como um diálogo íntimo de perspectivas em quaisquer processos decisórios. O fato é que em nenhum momento, numa experiência normal, vivo essa miríade de perspectivas, essa pluralidade de Eus de forma fragmentada, mas sempre 
sob o signo de uma unidade. Isso porque, como consciência é eterno desvelar-se e movimento, a perspectiva de tensão de forças, como Senhor, Escravo, mas também a "supressão dialética" desse embate na forma desta unidade, estão em contínua operação.

No entanto, na experiência esquizofrênica tem-se uma alteração desse jogo de forças intrassubjetivo, de tal monta que tais partes não são integradas na forma de um nós (Eu e um não-Eu), que é um eu, e as distintas partes emergem, quando não integradas, como ameaça à autonomia e como destruição mútua. Nessa conjuntura de partes não integradas, a relação tornase estática, tensa, e há uma insuficiência dessa dinâmica de supressão dialética.

Para ilustrar tal situação, tomemos o capítulo: "Reflexão e si nos esquizofrênicos" (Kimura, 1992). Neste, o autor propõe-se a examinar, inicialmente, o problema do excesso de reflexão nos esquizofrênicos. Ressalta que as pesquisas psicopatológicas abordam a dicotomia eu e si, e, para tal, cita os trabalhos de Nagai Mari.

Ela circunscreverá dois tipos de reflexão: a primeira é a subsequente, após um evento, quando se retoma, retrospectivamente, sobre suas próprias ações, relativamente comum a uma experiência de normalidade; e a segunda, uma reflexão simultânea, como em uma autoobservação constante, evocando um eu e um si. Esta última é raramente vivida numa experiência normativa.

Ainda a propósito desta última, há uma citação de um paciente, cuja descrição é muito arguta quanto a traduzir esse processo de fragmentação. Cito em tradução livre: "Em sociedade há sempre dois Eus. Quando o primeiro se encontra engajado em sociedade, o segundo observa tudo objetivamente. Qualquer que seja o entusiasmo com o qual eu participo na companhia dos outros, o segundo eu permanece a me observar imperturbavelmente de fora" (Kimura, 1992). ${ }^{2}$

O exemplo não parece remeter a um caráter radical de cisão desses eus, no qual embora haja um eu que observa e um eu observado, ambos coincidem na mesma experiência psicológica. Essa tensão entre duas forças antagônicas de reconhecimento intrassubjetivo encontra sua supressão dialética na forma de uma unidade, um nós que é eu.

No entanto, na esquizofrenia paranoide, um desses polos do eu sofreria uma "estrangeirização" (Fremdheit). O caráter de cisão é tão radical, que se perde o caráter de próprio. Dirá ainda que se tal "alterização" (Verfremdung) ocorre no eu que reflete, segue-se uma experiência de um delírio de observação, o de ser observado pelos outros. Se por sua vez é o eu refletido que é estrangeirizado (Verfremdet), vive-se o delírio de influência.

\footnotetext{
2 "En société il y a toujours deux "moi". Quand le premier moi se trouve engagé en société, le second observe tout objectivement. Quel que soit l'enthousiasme avec lequel je participe à la compagnie des autres, le deuxième moi reste à m' observer imperturbablement du dehors" (Kimura, 1992).
} 
Para situar no exemplo dado acima: Eu reparo que eu observo o pássaro. Se é o eu sujeito da frase que adquire o caráter cindido, há uma espécie de eterna sombra que acompanha, num paralelismo, este eu. Se, por sua vez, temos o eu do predicado estrangeirizado, seria como se este observar não lhe pertencesse.

O termo estrangeiro é uma boa figuração desse processo dado como uma alienação interna, a que o paciente é submetido. Essa chave hermenêutica na apreensão dos fenômenos permitiria que se compreendesse não somente os exemplos acima citados, mas também relatos de telepatia, roubo e inserção de pensamento, divulgação de pensamentos, perda de delimitação do eu, objetificação mórbida, alucinações verbais (compreendida como objetificação mórbida de um diálogo íntimo) (Stanghellini, 2003), etc. Todos esses fenômenos guardariam a marca da alienação de vivências que, numa experiência normal, são vividos tacitamente como próprios, referindo-se a uma Gestalt marcadamente alterada em seu fundamento subjetivo (Stephensen, 2018).

É possível destacar um outro aspecto da consciência-de-si: se mais acima destacamos o aspecto reflexivo como um jogo de espelhos, há ainda uma segunda acepção de reflexo, à semelhança do reflexo patelar, ou de quaisquer arco-reflexos fisiológicos, que é o fato de que estes ocorrem de maneira automática - não se trata de um processo deliberativo, já que circunscrevem uma arquitetura tácita, que somente na fragmentação se tornam explícitas. Esse processo tácito, Bin Kimura chamará de um estado de "esquecimento de si" ("cet état 'd'oubli de soi "'), pois não há a tematização de um eu.

É exatamente pelo fato de que essa reflexão simultânea se dá de forma tácita é que é possível engajar na vida pragmática, no polo dos objetos. Ao contrário, quando se perde tal e essa reflexão tácita fica explícita e tematizada, quando não fragmentada, o eixo desloca-se do polo noemático para o noético e consequentemente têm-se os processos hiper-reflexivos, nos quais os pacientes esquizofrênicos tematizam a própria vida mental como um objeto de consciência (Stanghellini, 2003). Tem-se então a transição, por exemplo, da modalidade "Observo a árvore", de um eu, sujeito da frase, silencioso, que pode simplesmente ser subtraído sem prejuízo da compreensão, para "Eu me vejo observando a árvore", instaurando uma distância entre mim e mim mesmo. O “eu” psicológico, empírico, único numa experiência normal, ocupará uma representação gramatical dupla, como sujeito e objeto, simultaneamente. No limite dessa experiência de um contínuo distanciamento desses eus, haverá uma fragmentação e não coincidência psicológica, empírica deles.

É curiosa, embora não explorada em minúcia no texto de Bin Kimura, a ideia de que uma reflexão simultânea somente pode ser feita por meio da apropriação da língua. Na verdade, 
parece-me, a língua pode aparecer como a figuração de um sistema de coordenadas, na forma de signos, que dê conta desta situação dúbia, na qual a aquisição de perspectiva de si para consigo próprio faz com que o "eu" ocupe a posição dupla de sujeito, como ponto zero, e objeto, como distância distinta do ponto zero. No entanto, a língua não é signo, como aquisição de sentido fora de si, mas é expressiva em si. A discussão, no entanto, daria uma tese em si e mereceria ser analisada em minúcia em outro momento, mas o curioso é o ensejo de que se a reflexão simultânea somente pode ser feita por meio da aquisição de uma língua e supondo tal atributo exclusivo dos seres humanos, a esquizofrenia seria, por conseguinte, uma condição exclusivamente humana. Isso não quer dizer que outros animais não se comuniquem entre si, mas sim que a língua teria uma complexidade superior a um mero suporte de signos. Baker (2000) argumentará nesse sentido, de que possuir consciência de si envolve não somente uma atitude perspectivista (eu versus um não-eu), já que seria preciso conceituar tal distinção, o que implica ter um aparato linguístico para usar o pronome em primeira pessoa para referir-se a si próprio.

Outra afirmação feita pelo autor é de que a esquizofrenia seria uma "patologia da intersubjetividade", de uma referência do sujeito ao sujeito.

A mesma intercambialidade dúbia, presente em Hegel, está presente aqui, afinal tratase de uma referência entre sujeitos, ou uma referência intrassubjetiva, na qual se constitui esse embate entre sujeitos, como na dialética Senhor-Escravo? Bin Kimura suplanta tal dubiedade ao dizer que o si constitui-se como princípio dessa referência ao outro sujeito, ou seja, é por que a consciência-de-si fundamenta-se tendo em si a estrutura da alteridade, num jogo de forças entre um eu e um não-eu, é que ela pode conceber um outro como outro, que é um não-eu, mas que se assemelha a um eu. Há um paralelismo intra e intersubjetivo. Aqui vale um adendo, pois o autor nos lembra que em japonês a palavra aida refere-se a um intervalo, seja ele espacial ou temporal. Para além disso é também uma marca distintiva da cultura japonesa que compreenderia o fundamento da existência como um fundamento social interpessoal. Seria como se primeiramente se desse esse ser-entre, como um nós, que não é um eu mais um tu, trata-se de uma totalidade que não é a soma das partes, um "lugar comum originário dessas múltiplas existências" (Kimura, 1992, p. 37) mas que forjará, num segundo momento, as partes que trarão em si essa marca, de um próprio e um não próprio embutidos, ou um aida intersubjetivo, que nos parece mais intuitivo, mas também um aida intrassubjetivo, menos intuitivo. Nesse sentido, é uma construção que se dá num paralelismo muito semelhante ao proposto por Hegel, quanto à introjeção da alteridade. 
Talvez um ponto de dissociação entre ambos os modelos é que, se para Bin Kimura num primeiro momento tem-se um aida originário, um ser-entre que forjará num segundo momento as partes Eu-Tu, para Hegel a genealogia segue da afirmação das partes como um "Em-si" e um "Ser-para-si” em direção a uma síntese dialética. No entanto, ambos partilham de uma mesma tradição, muito explorada em filosofia, quanto à posição de que a consciência e a noção de um Eu são socialmente constituídas, sendo a subjetividade somente possível de ser concebida num contexto social, de uma "comunidade de mentes" (community of minds), em contraposição a uma longa tradição moderna, cartesiana, de uma res cogitans anterior e subjacente (Zahavi, 2009).

Na relação intersubjetiva/intrassubjetiva Senhor-Escravo, que culmina numa supressão dialética das partes, numa síntese, numa Aufhebung, na qual esse eu-tu é também um nós, é justamente essa síntese que não é processada em sua plenitude na experiência esquizofrênica, donde as partes permanecem alterizadas e hipostasiadas. Diagnóstico semelhante é encontrado em Stephensen (2018), quando da afirmação de que a experiência esquizofrênica radical de alienação de si é o reflexo de uma "solidificação" de uma forma de diferenciação ou alteridade potencial implícita na natureza dinâmica da subjetividade. Bin Kimura dirá que na esquizofrenia a constituição intersubjetiva do si-mesmo não se enraiza no arché-aida. $\mathrm{O}$ impacto sofrido por essa consciência, impossibilitada quanto a esse conceber-se a si, conduz a uma situação crítica, pois se é este perder-se que conduz a um tipo de conhecimento, a um encontrar-se, essa alienação permanente conduz a uma espécie de reflexão em curto circuito permanente sobre si-mesma numa "tentativa de reestabelecer a subjetividade de si ameaçada de desaparecer" ( "tentative pour rétablir la subjectivité du soi menacé de disparition”).

Pode-se hipotetizar aqui o caráter hostil da experiência esquizofrênica, marcado pela persecutoriedade, ameaça de aniquilação e desintegração do Ego. Tomando-se as distintas fases que marcam a dialética Senhor-Escravo e supondo-se que esse processo, o qual culminaria na supressão dialética, não se dá em sua plenitude, o que se tem é um primeiro momento não integrativo em que a alteridade é sinônimo de ameaça à existência própria. Seria como um Outro intrassubjetivo, não integrado, vivido como externo, que impõe uma constante ameaça de desintegração a esse Ego. É justamente esse caráter de uma existência em constante ameaça de fragmentação que dá subsídios a Jaspers (1997) para pensar o porquê do caráter de incorrigibilidade do delírio.

Fez-se referência até aqui quanto aos estigmas subsidiários do aida intrassubjetivo, no entanto, como há um paralelismo nessa relação intra-intersubjetivo, é possível discorrer também quanto a apresentações peculiares no trato interpessoal como comportamentos sociais 
bizarros, embotamento afetivo, reações abruptas e uma falta de naturalidade, no geral. Fuchs transcende essa cisão dentro-fora quando de sua noção de um self corporificado ("embodied self'), figurando uma consonância entre os transtornos do self na esquizofrenia e uma inserção no mundo e interpessoal marcadamente alteradas (Fuchs, 2015).

Por fim, o problema central na reflexão esquizofrênica não diz respeito a um outro específico (der Andere), mas sim ao problema da alteridade (das Andere), que é um outro para a consciência-de-si, não integrado. Não por outro motivo é que a ênfase terapêutica é colocada quanto a restabelecer o si do paciente, para torná-lo apto às exigências interpessoais cotidianas. Nesse sentido, a psicoterapia como elemento chave é fundamental ao tratamento. Tanto é que aquilo que se vê como estigma e sintoma, sejam alucinações, delírios etc., e a que os neurolépticos conseguem dar uma resposta, Bin Kimura os vê também como último bastião de resistência dessa existência em xeque. Segue-se que uma resposta farmacológica sem o anteparo psicoterápico seria expor essa existência a um desespero, que poderia culminar em suicídio. 


\section{Referências Bibliográficas}

Baker, L. R. (2000). Persons and Bodies. Cambridge: Cambridge University Press.

Hegel, G. W. F. (2014) Fenomenologia do espírito. 9. ed., trad. Paulo Menezes. Petrópolis, RJ: Vozes: Bragança Paulista: Editora Universitária São Francisco.

Kimura, B. (1992). Ecrits de psychopathologie phénoménologique. Presses Universitaires de France.

Kojève, A. (1947) Introduction à la lecture de Hegel. Éditions Gallimard.

Jaspers, K. (1997) General Psychopathology. Translated by J. Hoenig and Marian W. Hamilton. The John Hopkins University Press.

Stanghellini et al. (2003). Auditory verbal hallucibations - breaking the silence of inner dialogue. Psychopathology, 36(3), 120-8, May-Jun 2003.

Stephensen, H. et al. (2018) What can self-disorders in schizophrenia tell us about the nature of subjectivity? A psychopathological investigation. Phenom Cogn Sci, 17, 629-642.

Fuchs, T. (2015). Pathologies of Intersubjectivity in Autism and Schizophrenia. Journal of Consciousness Studies, 22(1-2), 191-214.

Zahavi, D. Is the self a social construct? December 2009. Inquiry, 52(6), 551-573. 